\title{
Bisfenol A induce la senescencia en células del endotelio aórtico de ratón.
}

\author{
Alfonso Rodrigo Porcel, Marta Saura Redondo ${ }^{a}$ \\ Unidad de Bioquímica y Biología Molecular, Departamento de Biología de Sistemas, Facultad de Medicina y Ciencias \\ de la Salud, Universidad de Alcalá, 28871 Alcalá de Henares, Madrid, España. \\ a. marta.saura@uah.es
}

Palabras clave: Bisfenol A; senescencia; ateroesclerosis; envejecimiento; endotelio

\section{Resumen}

El Bisfenol A (BPA) es un compuesto fenólico, al que estamos expuestos en nuestro día a día, debido a su alta presencia en envases y otros productos. Muchos estudios habían señalado ya a este compuesto como disruptor endocrino. En este estudio nos plantemos su papel en la senescencia de células de endotelio vascular debido a la relación existente entre el BPA y la ateroesclerosis ya indicada por estudios previos. Ya se había observado que a altas dosis el BPA producía la muerte celular, pero los resultados obtenidos determinan que a bajas dosis el BPA $(10 \mathrm{nM})$ y en un tiempo de cinco días, produce senescencia en células de endotelio cardíaco murino determinado por cambios morfológicos en las células, aumento de la actividad $\beta-G a l$, y de la expresión de P53 y p16. Además, el BPA induce un fenotipo secretor asociado a la senescencia, generando un mayor número de microvesículas que tienen un efecto en la migración celular. Además, mediante ensayos de herida se demuestra un retardo en la migración celular a causa del BPA, así como una disminución de la producción de óxido nítrico. En conclusión, se ha determinado que el BPA a una concentración considerada como segura produce senescencia en las células del endotelio de ratón acompañado de disfunción del endotelio.

Cita: Rodrigo Porcel, Alfonso; Saura Redondo, Marta (2019) Bisfenol A induce la senescencia en células del endotelio aórtico de ratón. dianas 8 (2): e201909fa01. ISSN 1886-8746 (electronic) journal.dianas.e201909fa01 http://www3.uah.es/dianas?e201909fa01. URI http://hdl.handle.net/10017/15181

Copyright: ( $\odot$ Rodrigo-Porcel A, Saura-Redondo M. Algunos derechos reservados. Este es un artículo openaccess distribuido bajo los términos de una licencia de Creative Commons Reconocimiento-NoComercialSinObraDerivada 4.0 Internacional. http://creativecommons.org/licenses/by-nc-nd/4.0/

\section{Introducción}

El Bisfenol A (BPA) es un compuesto orgánico usado para la fabricación de policarbonatos y resinas epoxifenólicas. Este compuesto está siendo utilizado por la industria alimentaria para el envasado de productos frescos, y recubrimiento de recipientes de comida y bebida e incluso textiles [1]. Aunque el medio ambiente puede ser uno de los orígenes de la exposición al BPA, el principal medio de exposición son los alimentos [2]. Tras su ingesta, el BPA se metaboliza a varios metabolitos inactivos (BPAglucurónico y BPA-sulfato) y, a pesar de su rápida metabolización, se puede observar BPA libre en la orina de adultos y niños [2].

Numerosos estudios han alertado de sus posibles efectos nocivos para la salud, generando una importante polémica respecto al uso del BPA en materiales destinados al contacto con los alimentos. Por ello la Autoridad Europea de Seguridad Alimentaria (EFSA) ha realizado una nueva evaluación de esta sustancia en la que establece una ingesta diaria tolerable (IDT) temporal de $4 \mu \mathrm{g} \mathrm{kg-1} \mathrm{p.c.} \mathrm{día-1.} \mathrm{[3].}$

En el sistema cardiovascular, la exposición a BPA se ha relacionado con el desarrollo de hipertensión arterial, disfunción endotelial y aterosclerosis tanto en animales de experimentación como en humanos [4]. La hipertensión es un destacable factor de riesgo, que puede conducir a una enfermedad cardiovascular. En un estudio realizado en 2012 con humanos, se analizó la relación entre los niveles de BPA en orina y la hipertensión, determinando que los niveles crecientes de BPA en orina estaban en relación positiva con la hipertensión [5]. Así pues, se encontró una asociación estadísticamente significativa entre las concentraciones más altas de BPA y las enfermedades cardiovasculares y la diabetes, pero no con otras enfermedades comunes estudiadas [6]. Los estudios en animales también sugirieron que la exposición al BPA puede tener un papel en el desarrollo de la hipertensión a través de varios mecanismos, incluido el papel del BPA en el aumento de peso y el desarrollo de la obesidad principalmente a través de sus acciones sobre los preadipocitos, su papel como un xenoestrógeno [5].

Otros estudios propusieron que el BPA es causante de daños vasculares principalmente ateroesclerosis, sugiriendo que el BPA podría contribuir al daño oxidativo a las células endoteliales, esto se respalda con una correlación positiva entre el BPA urinario y marcadores de estrés oxidativo en un estudio realizado con 960 adultos [7]. 
Antecedentes de nuestro grupo indican, además, que genes como angiotensina II y calcio-calmodulina quinasa II (CaMKII), implicados en regulación vascular, se activaban en ensayos con células endoteliales murinas tratadas con BPA. Más tarde se comprobó que esa activación también sucedía in vivo siendo dicha activación la responsable de la disfunción endotelial e hipertensión [8].

Se sabe que el BPA afecta de diversas maneras al organismo. En un estudio [1] se comprobó que la exposición a BPA alteraba la expresión de dos mil genes involucrados en diferentes vías canónicas y procesos celulares en ausencia de citotoxicidad. Dado el nivel de exposición continua a bajas dosis de BPA, la hipótesis de este estudio es que el BPA induce senescencia acelerada del endotelio vascular siendo esta la base de la asociación entre BPA y ECV.

La senescencia celular es un estado de detención del ciclo celular asociado con el envejecimiento inducido por señales mitogénicas, daño al $\mathrm{ADN}$ e inflamación [9,10]. Las células senescentes secretan activamente señales auto y paracrinas, como citoquinas inflamatorias. Este fenotipo secretor asociado a la senescencia (SASP) inicia un círculo vicioso de inflamación y senescencia, que se cree que conduce a la enfermedad cardiovascular.

Existen dos tipos de senescencia, la replicativa y la inducida por estrés [11]. Además del acortamiento de los telómeros, también existen otras causas que inducen la detención del ciclo in vitro, como ciertas lesiones en el ADN y especies reactivas del oxígeno. Ambas activan la respuesta al daño en el ADN, una vía de señalización en la que las quinasas ATM o ATR bloquean la progresión del ciclo celular a través de la estabilización de p53 y la activación transcripcional del inhibidor de las quinasas dependientes de ciclinas (Cdks) p21 [15].

Algunos estudios ya han relacionado la senescencia endotelial con enfermedades asociadas a la edad, como es la ateroesclerosis [13]. Una célula endotelial senescente presenta varias anomalías funcionales, como la pérdida del potencial replicativo y una mayor susceptibilidad a ataques patológicos [14]. En el caso de las células del endotelio senescentes, se produce una pérdida de la expresión de eNOS, además de mostrar unos niveles de NO reducidos. La pérdida de eNOS puede deberse a la pérdida del regulador positivo AKT, o al aumento de moléculas inhibidoras, como la caveolina-1 [16]. En el caso de senescencia inducida por estrés, se pueden activar vías que involucran a p53/p21 y a p16/RB [17] y contribuir a cambios en la expresión genética, y la remodelación de la cromatina, que a su vez se relacionan con la senescencia, con el fenotipo secretor asociado a la senescencia (SASP) y con cambios en la morfología. Por ello en este estudio, estudiaremos la expresión de p53, p21 y p16 y cuantificaremos si existe un aumento de microvesículas, fruto de este fenotipo secretor senescente, en células tratadas con BPA y que efecto podrían tener las mismas sobre células normales.

\section{Materiales y métodos}

\section{Cultivos celulares}

En el estudio se utilizaron células de endotelio aórtico de ratón (MAEC) que fueron extraídas de aortas de ratones C57BL6 mediante explante en matrigel seguidas de selección en un sorter celular usando marcadores endoteliales (VACM-1 y VE Cadh), según protocolos previos de nuestro laboratorio [18] . Está purificación se corroboró mediante microscopía confocal de las células MAEC teñidas con ICAM-2 y vWF (BD, Biosciences, Europe), la pureza de las células usadas para los experimentos fue superior al 99\% [19]. Para el cultivo de estas células se utilizó el medio Dulbecco's Modified Eagle's Medium (DMEM F12), al que se añadieron los anticuerpos la anfotericina B al 0,5\% (Merck) y penicilina estreptomicina al 1\% (Merck), además de suero fetal bovino al 10\% (Merck). Las células crecieron con un aporte del $5 \%$ de $\mathrm{CO} 2$.

\section{Tratamiento con BPA}

Se utilizaron las concentraciones de 1nM y 10nM de BPA, para tratar las MAEC a diferentes tiempos 3, 5 y 7 días, en placas de 24 pocillos. Debido a los mecanismos de detoxificación celulares se realizó un retratamiento con BPA a las células cada 3 días.

\section{Detección de la senescencia}

Para la detección de la senescencia se utilizó el Senescence Detection Kit (abCam), que nos permitió observar por histoquímica la actividad SA- $\beta$-Gal en células en cultivo. Esta actividad SA- $\beta$-Gal está presente solo en las células senescentes, no apareciendo en células quiescentes, pre-senescentes o inmortales. La actividad nombrada se basa en el aumento del contenido lisosomal de las células senescentes [12]. Para esta detección, primero se lavaron las células con PBS 1x (Sigma-Aldrich), tras ello se fijaron con una solución fijadora (abCam) durante 15 minutos, tras ello se lavaron de nuevo y se procedió a tratar las células ya fijadas con una solución de tinción previamente preparada formada por un suplemento de tinción (abCam), una solución de tinción (abCam, y Xgal (abCam) diluido en dimetil sulfóxido (Sigma-Aldrich). 
Se incubó toda la noche a $37^{\circ} \mathrm{C}$. Pasadas las 12 horas se visualizaron las células al microscopio (Nikon DIAPHOT 300 con cámara Moticam 10.0), y se realizaron ocho fotografías por pocillo, en diferentes áreas del mismo valiéndonos del objetivo 10X. Después se realizó un conteo de células senescentes y totales.

\section{Estudio de la viabilidad celular}

Para la detección de la muerte celular se utilizó un ensayo de viabilidad celular por reducción del compuesto MTT, primero se lavaron las células con PBS y tras ello se añadió MTT, tras la reducción del MTT se retiró el medio y previo a la cuantificación se disolvió en dimetil sulfóxido (Sigma). Se midió su intensidad de color mediante la A570. La reducción del MTT se debe a las deshidrogenasas mitocondriales, concretamente a la succinato deshidrogenasa, pero también pueden intervenir reductasas citosólicas o de otros compartimentos subcelulares.

\section{Extracción de microvesículas}

Para la extracción de microvesículas se utilizaron los sobrenadantes de las distintas placas tratadas con BPA a las concentraciones ya indicadas y sus respectivos controles. Se realizaron tres centrifugaciones de dichos sobrenadantes a $11461 \mathrm{rpm}$ durante 15 minutos, a $12514 \mathrm{rpm}$ durante 5 minutos y a $20646 \mathrm{rpm}$ durante 45 minutos hasta finalmente aislar las microvesículas que a través de citometría de flujo utilizando el modelo FACSCalibur (Becton Dickinson), se pudieron cuantificar. Para el proceso de análisis mediante citómetro primero se añadió añadieron $300 \mu \mathrm{l}$ de Binding Buffer y después anexina $\mathrm{V}$ para su marcaje de manera calcio dependiente debido a la presencia de fosfatidil serina en su membrana y se mantuvieron en oscuridad durante 15 minutos, para poder normalizar los resultados, se añadieron a las muestras unas "bolas fluorescentes de conteo" (Flow-Count Fluorospheres, Invitrogen) para asegurarnos de pasar la misma cantidad de muestra en cada medida. Posteriormente los resultados obtenidos del citómetro fueron analizados mediante Cyflogic (2016), para determinar si las diferentes concentraciones de BPA inducían a las células a producir un mayor número de microvesículas.

En un segundo análisis con citometría de flujo, se utilizó Tritón X100 (Sigma-Aldrich) para que los eventos de naturaleza lipídica se degradaran (MV), y al analizarlas una segunda vez en el citómetro solo aparecen aquellos eventos correspondientes a contaminación de la muestra.

\section{Extracción de proteínas y Western Blot}

Una vez lavadas las células, se lisaron mediante tampón lisis (Bio-Rad) y se realizó una centrifugación a $11000 \mathrm{rpm}$ durante 15 minutos. Tras ello se realizó una determinación de las concentraciones de proteína mediante el método de Bradford (Quick start Bradford 1x Dye Reageant Bio-Rad).

La electroforesis se realizó en un gel de acrilamida (Bio-Rad) al 10\% para determinar la presencia de proteínas de marcadoras de senescencia, y también las ciclinas E y otros anticuerpos (Tabla 1). Se utilizaron las proteínas aisladas correspondientes a los dos tratamientos (1 nM y $10 \mathrm{nM})$ y al control.

Tras transferir el gel a una membrana de PVDF (Thermo Scientific) y antes de incubar con la solución de bloqueo se realizó una tinción con Rojo Ponceau (Termo Fisher), para valorar que los geles se habían cargado de forma correcta. La incubación se hizo durante toda la noche a cuatro grados con todos los anticuerpos utilizados (TABLA 1) tras 3 lavados con TTBS 1x (TBS en H2O destilada y $1 \mathrm{ml}$ Tween) se incubaron durante una hora ambas membranas con el anticuerpo secundario y tras 3 nuevos lavados con TTBS 1x se procedió al revelado utilizando Pierce ECL Western blotting substrate (Thermo Scientific), como reactivo quimioluminescente, y el lector Fusion Solo $3 \mathrm{~S}$ (Vilber Lourmat). Las imágenes se cuantificaron con Image $\mathbf{J}$ y posteriormente se analizaron mediante Microsoft Excel (2016).

\begin{tabular}{|c|c|c|c|}
\hline Anticuerpo & Casa comercial & Referencia & Anticuerpo secundario \\
\hline $\mathrm{p} 53$ & $\begin{array}{c}\text { Cell Signalling } \\
\text { Tecnology }\end{array}$ & $9282 \mathrm{~S}$ & $1: 1000$ \\
\hline $\mathrm{p} 21$ & eBioScience & $14-6715-81$ & $1: 600$ \\
\hline $\mathrm{p} 16$ & abCam & ab51243 & $1: 1000$ \\
\hline Ciclina E & NeoMarkers & RB-9228-p1 & $1: 600$ \\
\hline GAPDH & Sigma & G8795 & $1: 300$ \\
\hline PeNOS & Cell Signalling & $9571 \mathrm{~S}$ & $1: 1000$ \\
\hline CD31 & abCam & ab28364 & $1: 500$ \\
\hline
\end{tabular}

Tabla 1.-Anticuerpos utilizados para WB. 


\section{Cierre de herida}

Se sembraron células MAEC en una placa de seis pocillos a una concentración 10000 células $/ \mathrm{ml}$. Se trataron con BPA a una concentración $10 \mathrm{nM}$. Se mantuvo la placa durante cinco días, con un nuevo tratamiento a los tres días, una vez pasados estos se realizó una herida tanto en los controles como los pocillos tratados, utilizando una punta de micropipeta. Se tomaron microfotografías del avance de la herida (Nikon DIAPHOT 300 con cámara Moticam 10.0) con el objetivo 10x. Y los resultados del cierre se cuantificaron mediante Image $\mathrm{J}$.

Por otro lado, se repitió el mismo proceso, pero en lugar de tratar las células con BPA, se realizó un tratamiento de las mismas con las microvesículas aisladas previamente, mediante centrifugaciones seriadas.

\section{Inmunofluorescencia}

Se sembraron células MAEC, sobre cristales dispuestos en placas de veinticuatro pocillos, tras el tratamiento de cinco días se retiró el medio de la placa, se lavó con PBS 1x, y se fijaron las células con paraformaldehido al 4\% en PBS, las células se permeabilizaron con tritón al 0,5\%. Tras lavar con PBS, se bloqueó con BSA al 5\% en PBS a $\mathrm{T}^{\mathrm{a}}$ ambiente durante media hora. Se añadió el anticuerpo primario CD31 (Tabla 1) a una concentración 1:20. Se mantuvo a $4^{\circ} \mathrm{C}$ durante la noche. Tras dos lavados, se añadió el anticuerpo secundario marcado con FITC durante una hora a $\mathrm{T}^{\mathrm{a}}$ ambiente. Se incubó con el colorante Hoechst que nos permitiría posteriormente visualizar los núcleos marcados en azul. Se lavó con PBS 1x y se dispusieron los cristales en portaobjetos donde se les añadió FluorSave para preservar la fluorescencia de las muestras. Tras ello se visualizaron las mismas en el microscopio de fluorescencia.

\section{Cuantificación de superóxido}

Las placas p60 con células MAEC senescentes tras la exposición a BPA, se preincubaron con L-NAME $\left(10^{-6} \mathrm{M}\right) 16 \mathrm{~h}$, tras lo que se trataron con apocinina $10 \mathrm{nM}$ (Sigma)para inhibir la NADPH oxidasa durante una hora. Posteriormente se lavaron se tripsinizaron las células y en PBS con la sonda dihidroetidio (DHE) (Invitrogen) se mantuvieron los tubos de citómetro en oscuridad y tras treinta minutos se realizó la lectura. Para obtener la medida de la autofluorescencia, algunas muestras se incubaron sólo con PBS.

\section{Cuantificación de óxido nítrico}

Tras dos lavados con PBS 1x se incubó con la sonda DAF (Cayman Chemical Company) durante una hora y media. Quince minutos antes de que se cumpliese ese tiempo indicado se añadió el Ionóforo de Calcio (Sigma-Aldrich). Tras ello se levantaron las células por los medios habituales, tras una centrifugación (1800 rpm/5 minutos) se resuspendieron en PBS 1x y se realizó la lectura al citómetro tras añadir Ioduro de propidio (Sigma-Aldrich).

\section{Análisis estadístico}

Cada experimento se repitió como mínimo dos veces. El análisis se llevó a cabo con Microsoft Excel 2016, y el p valor se obtuvo a través del test de $\mathrm{t}$ de Student. Las desviaciones observadas son desviaciones estándar.

\section{Resultados}

\section{EI BPA induce senescencia en células endoteliales}

Primeramente, determinamos mediante un ensayo de viabilidad celular la dosis de BPA que no producía muerte celular en nuestras células. La viabilidad se determinó mediante MTT a diferentes tiempos, uno, tres y cinco días con diferentes concentraciones de BPA $(1 \mathrm{nM}-1 \mu \mathrm{M})$. Como se observa en la Figura $1 \mathrm{~A}$ el BPA produce muerte celular a partir de la concentración de $100 \mathrm{nM}$. Por ello nos centramos en las concentraciones inferiores a $100 \mathrm{nM}$ en las que estudiamos la inducción de senescencia.

Las células senescentes se diferencian por la expresión de distintos marcadores y cambios morfológicos incluyendo la actividad $\beta$-galactosidasa asociada a la senescencia y la expresión de supresores de tumores e inhibidores del ciclo celular. También aparecen marcadores de daño en el DNA, focos nucleares de heterocromatina constitutiva y secreción de moléculas de señalización [12]. Las células expuestas a BPA cambiaron de su forma habitual, a formas aplanadas e irregulares con un aumento de los residuos intracelulares después del tratamiento. A continuación, se realizó la determinación de la actividad $\beta$ galactosidasa con dos concentraciones de BPA $(1 \mathrm{nM}, 10 \mathrm{nM})$ y a distintos tiempos $(3,5$, y 7 días $)$. No se obtuvieron diferencias significativas en la tinción $\beta$-GAL entre CT y BPA a los 3 días de tratamiento, sin embargo, a los 5 días la tinción $\beta$-Gal aumentó de manera significativa tanto a $1 \mathrm{nM}$ como a $10 \mathrm{nM}$, siendo más acusada a $10 \mathrm{nM}$ (p valor=0,008), respecto al control (Figura $2 \mathrm{~A}$ ). A los 7 días se observó que las células entraban en apoptosis, especialmente a la concentración 10nM, por lo que el resto de los 
estudios se realizaron a 5 días tras el tratamiento con BPA. El supresor tumoral p53 y los inhibidores de CDK, p16, p21 y p27, participan en el arresto del crecimiento asociado a senescencia. Con el objetivo de comprobar si estos marcadores se encontraban alterados en presencia de BPA se realizaron ensayos de Western Blot (Figura 2B). Como se observa en la Figura 3, p53 y p16 se encontraban claramente aumentados en las células tratadas con BPA a las dos concentraciones (1 nM y $10 \mathrm{nM})$. Sin embargo, los niveles de p21 no resultaron afectados por nuestras condiciones experimentales. Además, se cuantificó ciclina E, observando una disminución a la concentración $10 \mathrm{nM}$ que concuerda con el fenotipo senescente. Otro marcador de senescencia es la presencia de focos de heterocromatina asociados a senescencia también se hizo patente a los 5 días de tratamiento de las células con una dosis de $10 \mathrm{nM}$ (Figura 2C).

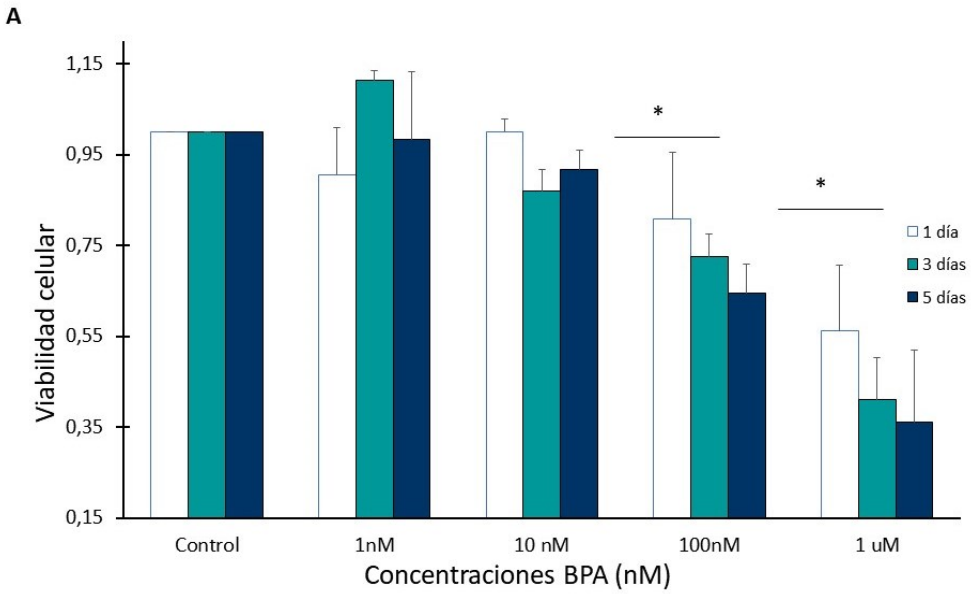

Figura 1.- Efecto del BPA en viabilidad de células MAEC y cuantificación del ciclo celular. A) Gráfica obtenida a partir de datos de ensayos MTT, se añadieron distintas concentraciones de BPA (1 $\mathrm{nM}, 10 \mathrm{nM}, 100 \mathrm{nM}, 1 \mu \mathrm{M})$ a cultivos de células MAEC, el ensayo de MTT se realizó a 1, 3 y 5 días. y mediante absorbancia se midió la viabilidad celular. $n=3(p<0,01)$

A

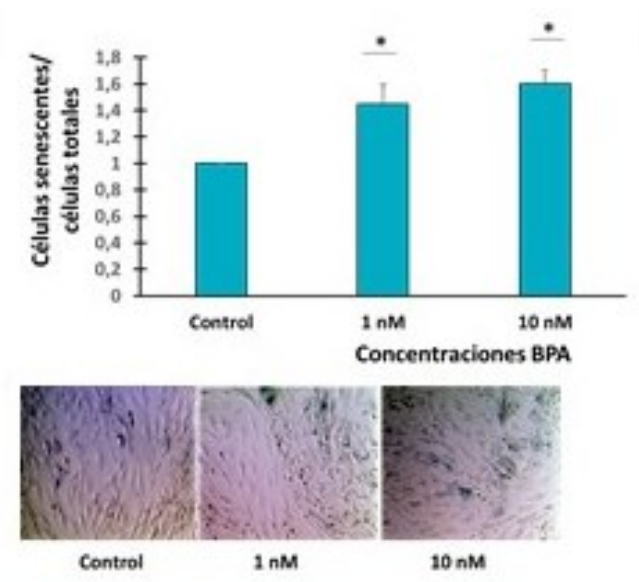

C

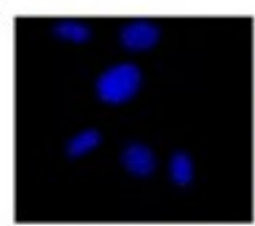

Control
B
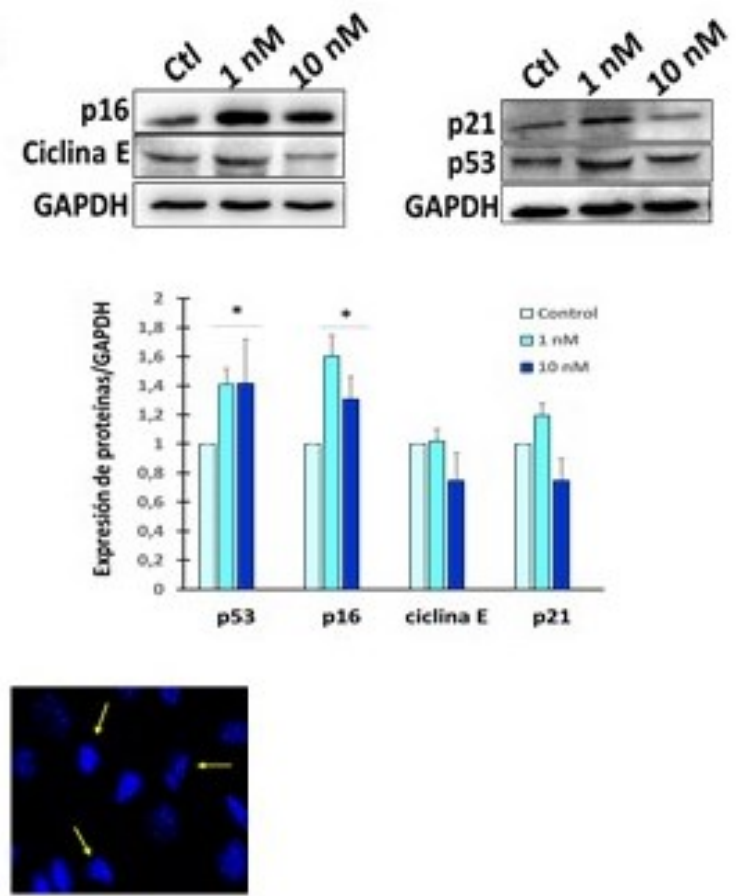

BPA $(10 \mathrm{nM})$

Figura 2.-BPA induce senescencia endotelial. (A) Gráfica realizada a partir de los datos obtenidos del conteo de células senescentes (teñidas en azul a través del kit de detección de SA-beta-gal) de fotografías del cultivo a cinco días de tratamiento con BPA $(n=5)(p<0,05)$, (B) Western Blot de p53, p16, p21 y ciclina E y GADPH como control de carga $(n=4)(p<0,05)(C)$. Microfotografía de los núcleos teñidos con DAPI, las flechas indican los núcleos con condensaciones de la heterocromatina. Los datos se expresan como media \pm desviación estándar $(n=3)$ 
Sumando estos datos, podemos concluir que el BPA a dosis bajas induce senescencia en células endoteliales.

\section{La senescencia inducida por BPA altera la función del endotelio}

Para determinar si la senescencia endotelial inducida por el BPA tenía algún efecto sobre las funciones biológicas de estas células se llevó a cabo un ensayo de reparación de herida endotelial a la dosis de $10 \mathrm{nM}$ (Figura 3A). Se realizaron fotografías a tiempo cero llegar al cierre de la herida a las 14 horas. Se comprobó que las células MAEC no tratadas son capaces de cerrar la herida a las 14 horas mientras que a ese tiempo las células MAEC tratadas con BPA, no habían terminado aún de reparar la herida.

Con el objetivo de determinar si la alteración existente en el endotelio altera alguno de los marcadores típicos endoteliales se realizaron Western Blot e inmunofluorescencia con CD-31/PECAM-1 (Figura 3C). Observamos que la concentración $10 \mathrm{nM}$ de BPA aumentaba la expresión del marcador de endotelio CD31 de forma significativa.

El empeoramiento de la función vascular es una de las características asociadas al envejecimiento [20] siendo esta un fuerte predictor de enfermedad cardiovascular [21][22][23]. El declive en la función vascular suele ser debido a una disfunción de la eNOS y no a una disminución de su expresión [24] [25] [26]. Por este motivo, estudiamos la liberación de NO procedente de las MAEC tratadas con BPA. Como se observa en la Figura 4, la producción de NO dependiente de la eNOS se vio reducida tras el tratamiento con BPA, sin embargo, al estudiar la producción de radical superóxido en unas condiciones en las que inhibimos la NADPH oxidasa observamos un aumento de la producción de superóxido indicando la existencia de un desacoplamiento enzimático de la eNOS. Este desacoplamiento es uno de los eventos clave en la disfunción endotelial ya que el superóxido generado junto con el escaso NO producido se combinan formando un radical con potencial citotóxico más potentes el peroxinitrito.

A

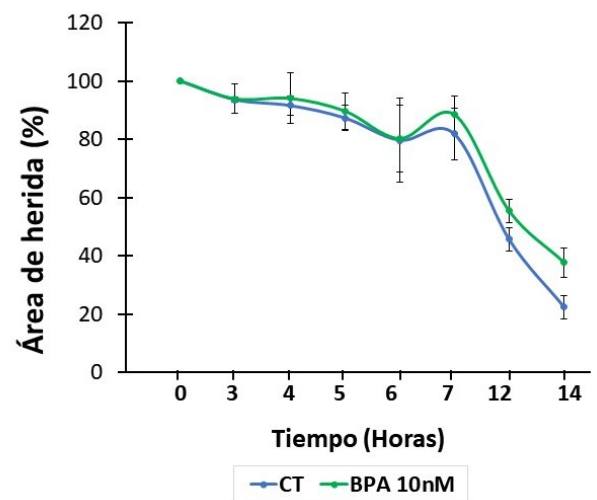

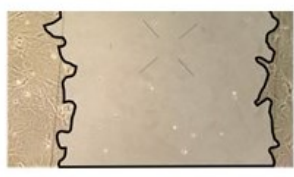

Control 2 horas

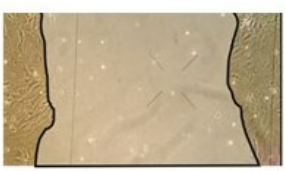

BPA 2 horas

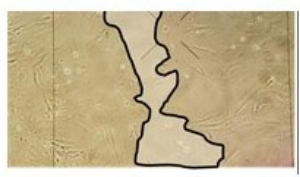

Control 14 horas

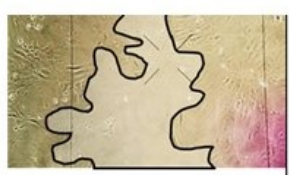

BPA 14 horas

B

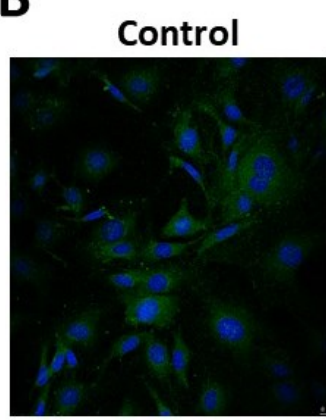

CD31/Núcleos BPA (10 nM)

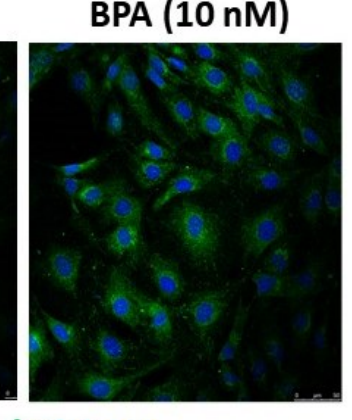

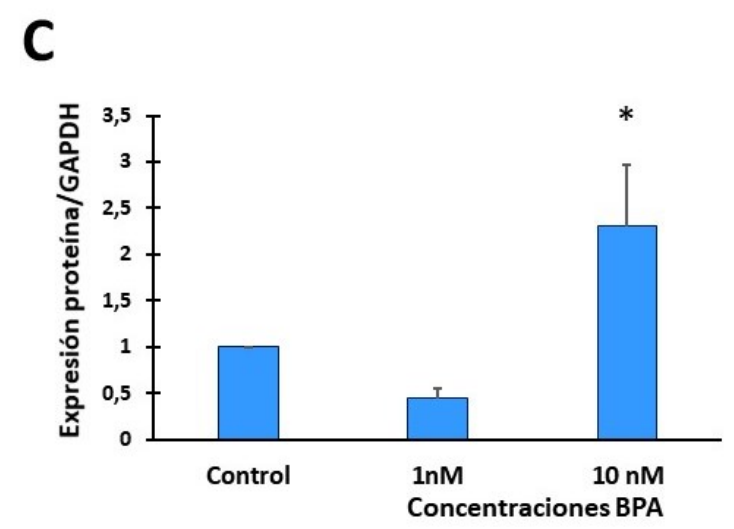

Figura 3.- Efecto del BPA sobre cierre de herida endotelial. A) Las células MAEC se trataron con BPA y se mantuvieron durante cinco días. Tras ello se realizó una herida endotelial, y se tomaron fotografías desde un tiempo cero hasta las 16 horas. El área de herida se analizó mediante ImageJ, en la gráfica se muestra la cuantificación del área. $(n=2)$ B) Inmunofluorescencia con anticuerpo CD31 C) Con los sobrenadantes de células tratadas a $1 \mathrm{nM}$ y $10 \mathrm{nM}$ con BPA, se realizó por WB con el anticuerpo CD31 $(n=4)$ 

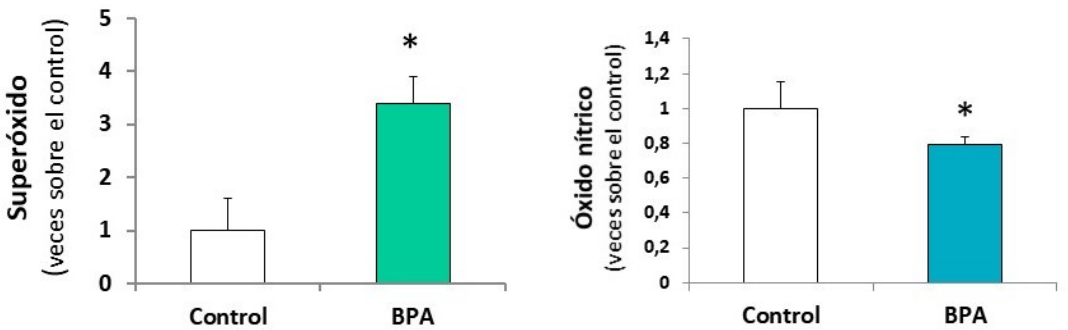

Figura 4.- Producción de óxido nítrico y superóxido en MAEC senescentes inducidas por BPA. Se cuantificó la producción de óxido nítrico y de radical superóxido a través de citometría de flujo mediante las sondas DHE (superóxido) y DAF (óxido nítrico). $\mathrm{n}=2(\mathrm{p}<0,05)$

\section{La senescencia inducida por BPA genera un aumento de la liberación de microvesículas endoteliales}

Una vez confirmado que el BPA podía inducir senescencia endotelial, el siguiente paso fue estudiar su efecto sobre el fenotipo secretor asociado a la senescencia. Se ha determinado que las células endoteliales senescentes producen un mayor número de microvesículas que las células jóvenes, pudiendo generar disfunción en otras células endoteliales [27]. Por lo tanto, nos propusimos estudiar si el BPA inducía la liberación de MVs de nuestras células y su actividad en otras células endoteliales.

En primer lugar, se realizó una cuantificación de microvesículas mediante citometría de flujo (Figura 5 A). Observamos que existe un aumento significativo de la cantidad de microvesículas en los medios de cultivo de las células tratadas con BPA (10nM) con respecto al control. Con estas MVs se realizaron dos aproximaciones, por un lado, se estudió si eran capaces por sí mismas de inducir senescencia en un cultivo de MAEC y por otro lado se estudió si producían alguna modificación en la reparación de una herida endotelial. La adición de MVs de las células senescentes inducidas por BPA, incrementó el número de células con tinción positiva para SA- $\beta$-GAL (Figura 5 B) indicando que estas MVs son capaces de comunicar señales que inducen senescencia.

Al añadir estas MVs a un ensayo de cierre de herida se observó que las microvesículas producen un efecto positivo en la reparación del endotelio acelerando el cierre de la herida, en comparación tanto con células control o tratadas con BPA. Las MVs procedentes de las células en las que el BPA había inducido senescencia repararon la herida aún más rápidamente. (Figura 5 C).

\section{Discusión}

Los resultados de nuestro estudio muestran que el bisfenol-A induce senescencia a dosis muy bajas, en nuestro estudio a la dosis de $10 \mathrm{nM}$, con la aparición de marcadores celulares característicos y la detención de la proliferación confirmando nuestra hipótesis de partida. Estudios recientes demuestran que las células endoteliales senescentes se acumulan en los vasos con la edad y en la ateroesclerosis y que estímulos proaterogénicos promueven la senescencia de células endoteliales en cultivos y en modelos animales [28][29][30]. La senescencia se puede inducir por varios mecanismos y se conocen dos modalidades de senescencia, la replicativa y la inducida por estrés [11]. En los vasos, la senescencia replicativa no se ha descrito con precisión, aunque se han encontrado células senescentes en placas de aterosclerosis in vivo [31]. El endotelio es especialmente sensible a todo tipo de estreses como el oxidativo o mecánico activando la senescencia inducida por estrés, entre los estímulos podremos incluir, como demuestra este trabajo la exposición a pequeñas concentraciones de BPA durante nuestra vida diaria.

Hemos determinado que la exposición a dosis superiores a $100 \mathrm{nM}$ cinco días es suficiente para producir muerte celular. Muchos estudios coinciden en que a la concentración de $100 \mathrm{nM}$ se produce un incremento significativo de la misma [32]. Un estudio realizado con células endoteliales de aorta bovina BAEC, demostró que el BPA a las concentraciones de $10 \mathrm{nM}, 100 \mathrm{nM}, 1000 \mathrm{nM}$, generó un aumento en la viabilidad, pero no en la proliferación [33]. Sin embargo, BPA induce en células tumorales un aumento de la proliferación y del crecimiento [2]. Estas aparentes discrepancias indican que el efecto del BPA sobre la proliferación y la viabilidad celular es especialmente dependiente del tipo celular.

Hemos determinado que existe un aumento significativo de los marcadores de p53 y p16, ambos participantes en la detención del ciclo celular. Varios estudios han determinado la existencia de una sobreexpresión de p53 regulada por la concentración de $100 \mu \mathrm{M}$ de BPA a las 24 horas, en fibroblastos de pulmón fetal humano HFLF conllevando una detención de ciclo celular y un aumento de la senescencia [1]. Los marcadores de senescencia (p16, p21, p53) también se correlacionaron significativamente con los niveles de BPA en un estudio con muestras de suero humano [34]. 

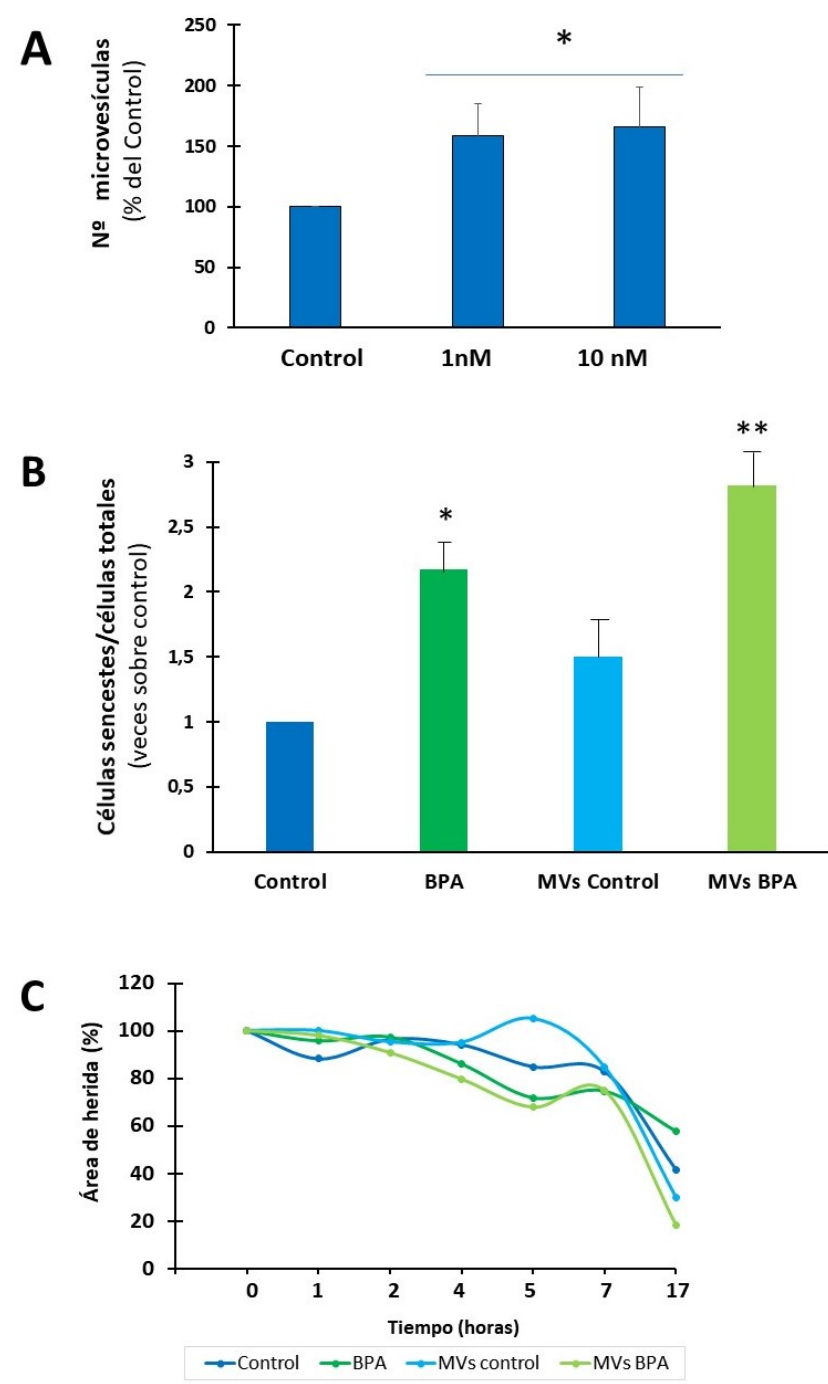

Figura 5.-Efecto de las MVs senescentes en células endoteliales. A) Gráfica obtenida a partir de la cuantificación de microvesículas aisladas por citometría de flujo, de sobrenadantes de MAEC tratadas con BPA. B) Efecto de las MVs aisladas sobre la senescencia de células MAEC medido por la actividad $\beta$-Gal. C) Efecto de las Mvs en un ensayo de cierre de herida, medido por cuantificación del área cerrada frente al Control. $(\mathrm{n}=2) *(\mathrm{p}<0,05) * *(\mathrm{p}<0,01)$

La senescencia del endotelio tras la exposición al BPA se tradujo en un empeoramiento de la capacidad de reparar una herida en la monocapa de células. Algunos estudios [35] realizaron ensayos de herida en células epiteliales de mucosa de colon NCM460, mostrando que a dosis similares a las nuestras no se inducía la reparación de la herida, sin embargo, en fibroblastos cardiacos con otras concentraciones más altas $(10 \mu \mathrm{M})$ y en tratamientos a 24 y 48 horas se encontró el efecto contrario [36]. Hay que resaltar que los tratamientos es estos estudios son modelos agudos y el nuestro es un modelo de exposición a cinco días por lo que no son totalmente comparables.

Por otro lado, un determinante clave de la función endotelial es la producción continua de NO a través de la eNOS. Nuestros resultados demuestran que la senescencia de las MAEC inducida por el BPA, reduce la producción de NO y aumenta la de radical superóxido-dependiente de eNOS debido al desacoplamiento enzimático de esta enzima. Estudios realizados anteriormente describen que el BPA incrementa la expresión de mRNA de eNOS pero en lugar de producir más NO, producía radical superóxido [8]. Otros autores han realizado el mismo experimento con otro tipo de células (HUVEC) y se determinó que se producía un aumento de p-eNOS y un aumento del NO [37]. Nuestro grupo ya había observado que a dosis en las que el BPA induce hipertensión, se produce un importante desacoplamiento enzimático de la eNOS donde además se induce la expresión de la misma [8]. El desacoplamiento de la eNOS encontrado en las células senescentes ha sido un hallazgo inesperado dado que la dosis utilizada se ha reportado como "segura", pero incluso a estas dosis se produce un endotelio disfuncional con la capacidad de amplificar el daño, puesto que el menor NO producido se combina con el superóxido formando un radical con potencial citotóxico más potente, el peroxinitrito [8].

Por otro lado, encontramos un aumento del marcador endotelial CD-31 o PECAM-1, en las MAEC tratadas con BPA. PECAM-1 es una proteína mecanosensitiva muy importante en la función endotelial al 
traducir las fuerzas de estrés hemodinámico en señales que aumentan la producción de NO por la eNOS [38]. Curiosamente, se ha descrito que tanto la expresión como la actividad de PECAM-1 aumentan en el envejecimiento tanto de células endoteliales microvasculares como en células progenitoras cardiacas [39] [40]. De esta manera, el aumento de la expresión de PECAM-1 refuerza la hipótesis de que el BPA induce envejecimiento acelerado del endotelio vascular.

El BPA induce la liberación de microvesículas por las células senescentes. Las vesículas extracelulares, las cuales abarcan exosomas y microvesículas, se ocupan de la comunicación célula-célula a través de la entrega de proteínas, lípidos y microRNAs a células diana mediante endocitosis [41]. Se ha visto que algunas presentan ceramida, un esfingolípido que se relaciona con un incremento de la apoptosis y la senescencia [42]. Estudios previos habían determinado ya que las microvesículas procedentes de tratamientos con diferentes compuestos tenían la capacidad de modular, en células progenitoras endoteliales, la expresión de p53 [43]. Las MVs se liberan ante diversos insultos celulares, en nuestro caso el estrés oxidativo y nitrosativo generado podría estar detrás de la liberación de las MVs [44].

El dato más sorprendente encontrado es que si bien las MVs de MAEC senescentes son capaces de comunicar esa señal a otras células e inducir senescencia, aceleran la reparación de una herida endotelial. Otros autores también han realizado este tipo de ensayos en células madre mesenquimales derivadas del tejido adiposo diabético tipo 2 (dAT-MSC) encontrando que la migración se veía mejorada tras el contacto con microvesículas[45]. Además, las células senescentes son metabólicamente muy activas, por lo que desarrollan un fenotipo secretor asociado a senescencia (SASP). El secretoma de las células senescentes es complejo e incluye factores que refuerzan el secuestro de la proliferación asociada a la senescencia, citoquinas que regulan el sistema inmunitarios y factores que remodelan la matriz extracelular como el aumento de la producción de la Metaloproteinasa de matriz 1 (MMP1) y MMP3, y la disminución de la expresión de fibronectina y colágeno. En general, el balance se inclina hacia la promoción de la degradación de la ECM. Por ejemplo, las MMP pueden degradar la ECM, y esto puede afectar la arquitectura del tejido y facilitar la migración celular. Dado que en nuestro experimento las MVs permanecen 5 días en el cultivo de MAEC es posible pensar que los factores solubles que expresan estas MVs induzcan en nuestras células un cambio en los patrones de expresión de matriz extracelular y MMPs, y que estos sean los responsables de la reparación acelerada observada como se ha descrito para varias metaloproteasas que actúan a través de NO [46][19]. El papel de la SASP en la aterosclerosis todavía es, en parte, desconocido, aunque se sabe que la SASP en las células vasculares senescentes humanas requiere IL $1 \alpha$, y causa disfunción de las células del endotelio y reclutamiento de células mononucleares.

Por tanto, concluimos que el BPA actúa como agente estresor induciendo senescencia en el endotelio vascular, generando una disminución de NO y un aumento del estrés oxidativo y produce una alteración que induce la sobreexpresión tanto de p53 como de p16, lo que conlleva un arresto del ciclo. Además, hemos podido comprobar que el BPA provoca el desarrollo del fenotipo secretor asociado a la senescencia induciendo la liberación de MVs. Aún queda por caracterizar plenamente el efecto que tienen las microvesículas producidas en estas condiciones y su contenido en las enfermedades cardiacas como la ateroesclerosis. En vista de nuestros datos, es posible afirmar que el BPA no causa un efecto citotóxico a las dosis autorizadas, pero hace envejecer prematuramente el endotelio de nuestros vasos, lo cual obliga a replantear la seguridad de las dosis de BPA recomendadas.

\section{Referencias}

1. Mahemuti, L.;,Chen, Q., Coughlan, M.C, Quiao, C., Chepelev, N.L., Florian, M., Dong, D., Woodworth, R.G., Yan, J., Cao, X., Scoggan, K.A., Jin, X., Willmore, R.G. (2018) Bisphenol A induces DSB-ATM-p53 signaling leading to cell cycle arrest, senescence, autophagy, stress response, and estrogen release in human fetal lung fibroblasts. Mol Toxicol. 92 (4): 1453-1469

2. Murata, M., Kang, J. (2018). Bisphenol A (BPA) and cell signaling pathways. Biotechnol Adv, 36(1), 311-327

3. Bustos, J., Santillana, M. I., Lomo, M.L., Ruiz, E. (2015) Estudios de prospección de bisfenol A y melamina en bebidas enlatadas. Revista del Comité Cientifico de la AECOSAN. 22: 151-164.

4. Bosch, R.J.; Quiroga, B.; Muñoz-Moreno, C.; Olea-Herrero, N., Arenas, M.I.; González-Santander, M., Reventún, P.; Zaragoza, C.; de Arriba, G.; Saura, M. (2016) Bisphenol A: An environmental factor implicated in renal vascular damage. Nefrología. 36(1): 5-9

5. Shankar, A, Teppala, S. (2012). Urinary bisphenol A and hypertension in a multiethnic sample of US adults. $J$ Environ Public Health, 2012: 1-5

6. Gao X., Wang H.S. (2014) Impact of Bisphenol A on the Cardiovascular System — Epidemiological and Experimental Evidence and Molecular Mechanisms. Int. J. Environ. Res. Public Health. 11: 8399-8413

7. Melzer, D., Gates, P., Osborne, N. J., Henley, W. E., Cipelli, R., Young, A., Money C, McCormack P, Schofield P, Mosedale D, Grainger D Galloway, T. S. (2012). Urinary bisphenol a concentration and angiography-defined coronary artery stenosis. PloS one, 7(8), e43378

8. Saura, M., Márquez, S., Reventún, P., Olea-Herrero, N, Arenas, M.I., Moreno-Gómez-Toledano, R., GómezParrizas, M, Muñoz-Moreno, C., Gónzalez-Santander, M, Zaragoza, C., Bosch, R.J. Oral administration of 
bisphenol A induces high blood pressure through angiotensin II/CaMKII-dependent uncoupling of eNOS. FASEB J. 28 (11): 4719-28

9. Hayflick, L., Moorhead, P.S. (1961) The Serial Cultivation of Human Diploid Cell Strains. Exp Cell Res. 25: 585-621

10. Campo-Trapero, J., Cano-Sánchez, J., López-Durán, M., Palacios-Sánchez, B., Sánchez-Gutierrez, J.J., BasconesMartínez, A. (2008). Marcadores de senescencia celular en cáncer y precáncer oral. SciELO. 24: 69-80.

11. Kida, Y.; Goligorsky, M. S. (2016) Sirtuins, cell senescence, and vascular aging. Can J Cardiol. 32 (5): 34-641

12. Muñoz-Espín, D.; Serrano, Manuel. Cellular senescence: from physiology to pathology. Nature Rev Mol Cell Biol. 15(7): 482-96

13. Gevaert A.B., Shakeri, H., Leloup, A.J., Van Hove, C.E., De Meyer, G.R., Vrints, C.J., Lemmens, K., Van Craenenbroeck, E.M. (2017). Endothelial Senescence Contributes to Heart Failure With Preserved Ejection Fraction in an Aging Mouse Model. Circ Heart Fail. 10(6): e003806

14. Tian, X.L.; Li,Y(2014) .Endothelial Cell Senescence and Age-Related Vascular Diseases. J Genet Genomics 41: 485-495.

15. van Deursen, J. M. (2014). The role of senescent cells in ageing. Nature. 509, 509, 439-446

16. Childs, B.G., Baker, D.J., Kirkland, J.L., Campisi, J., van Deursen, J.M. (2014). Senescence and apoptosis: dualeing or complementary cell fates? EMBO reports. 15(11): 1139-53

17. Tchkonia, T., Zhu, Y., van Deursen, J., Campisi, J., Kirkland, J. L. (2013) Cellular senescence and the senescent secretory phenotype: therapeutic opportunities. J Clin Invest. 123(3): 966-972.

18. Herranz, B., Marquez, S., Guijarro, B., Aracil, E., Aicart-Ramos, C., Rodriguez-Crespo, I., Serrano, I., Rodríguez-Puyol, M., Zaragoza, C., Saura, M. (2012) Integrin-linked kinase regulates vasomotor function by preventing endothelial nitric oxide synthase uncoupling: role in atherosclerosis. Circ Res. 110(3): 439-49.

19. Lopez-Rivera, E., Lizarbe, T.R., Martinez-Moreno, M., Lopez-Novoa, J.M., Rodriguez-Barbero, A., Rodrigo, J., Fernandez, A.P., Alvarez-Barrientos, A., Lamas, S., Zaragoza, C. (2005) Matrix metalloproteinase 13 mediates nitric oxide activation of endothelial cell migration. Proc Natl Acad Sci. 102(10): 3685-90

20. Seals, D.R., Jablonski, K.L., Donato, A.J. (2011) Aging and vascular endothelial function in humans. Clin Sci. 120(9): 357-75.

21. Widlansky, M.E., Gokce, N., Keaney, J.F., Vita, J.A. (2003) The clinical implications of endothelial dysfunction. $J$ Am Coll Cardiol. 42(7): 1149-60.

22. Deanfield, J.E., Halcox, J.P, Rabelink, T.J. (2007) Endothelial Function and Dysfunction Testing and Clinical Relevance Circulation 115(10): 1285-95

23. Green, D.J., Spence, A., Rowley, N., Thijssen, D.H., Naylor, L.H. (2012) Vascular adaptation in athletes: is there an 'athlete's artery'? Exp Physiol. 97(3):295-304.

24. Gryglewski, R.J., Palmer, R.M., Moncada, S. (1986) Superoxide anion is involved in the breakdown of endothelium-derived vascular relaxing factor. Nature. 320(6061): 454-6.

25. Guzik, T.J., West, N.E., Pillai, R., Taggart, D.P., Channon, K.M. (2002) Nitric oxide modulates superoxide release and peroxynitrite formation in human blood vessels. Hypertension. 39(6): 1088-94.

26. Fleming, I., Busse, R. (2003) Molecular mechanisms involved in the regulation of the endothelial nitric oxide synthase. Am J Physiol Regul Integr Comp Physiol. 284(1): 1-12.

27. Lovren, F., Verma, S. (2013). Evolving role of microparticles in the pathophysiology of endothelial dysfunction. Clin Chem. 59(8): 1166-74

28. Vasile, E., Tomita, Y., Brown, L.F., et al. (2001) Differential expression of thymosin beta-10by early passage and senescent vascular endothelium is modulated by VPF/VEGF: evidence for senescent endothelial cells in vivo at sites of athero-sclerosis. FASEB J. 15: 458 - 466.

29. Minamino, T., Miyauchi, H., Yoshida, T, et al. (2002) Endothelial cell senescence in human atherosclerosis: role of telomere in endothelial dysfunction. Circulation. 105: 1541-1544.

30. Rajapakse AG, Yepuri G, Carvas JM, et al. (2011) Hyperactive S6K1 mediatesoxidative stress and endothelial dysfunction in aging: inhibition by resveratrol. PLoS One. 6: e19237

31. Garrido, A.M., Bennett, M. (2016) Assessment and consequences of cell senescence in atherosclerosis. Curr Opin Lipidol. 27(5): 431-8.

32. Olea-Herrero, N., Arenas, M.I., Muñóz-Moreno, C., Moreno-Gómez-Toledano, R., González-Santander, M., Arribas, I., Bosch, R.J. (2014) Bisphenol-A induces podocytopathy with proteinuria in mice. J Cell Physiol. 229(12): 2057-66.

33. Liu, J., Jin, X., Zhao, N., Ye, X., Ying, C. (2015) Bisphenol A promotes X-linked inhibitor of apoptosis proteindependent angiogenesis via G protein-coupled estrogen receptor pathway. J Appl Toxicol. 35(11): 1309-17.

34. Soundararajan A1,2, Prabu P1, Mohan V1, Gibert Y2,3, Balasubramanyam M4. (2019) Novel insights of elevated systemic levels of bisphenol-A (BPA) linked to poor glycemic control, accelerated cellular senescence and insulin resistance in patients with type 2 diabetes. Mol Cell Biochem. :1-13

35. Shi, T., Zhao, C., Li, Z., Zhang, Q., Jin, X. (2016) Bisphenol a exposure promotes the migration of NCM460 cells via estrogen receptor-mediated integrin $\beta 1 /$ MMP-9 pathway. Environ Toxicol. 31(7): 799-807. 
36. Hu, Y., Zhang, L., Wu, X., Hou, L., Li, Z., Ju, J., Li, Q., Qin, W., Li, J., Zhang, Q., Zhou, T., Zhang, L., Xu, C.3, Fang, Z., Zhang, Y.(2016) Bisphenol A, an environmental estrogen-like toxic chemical, induces cardiac fibrosis by activating the ERK1/2 pathway. Toxicol Lett. 27: 250-251

37. Andersson, H., Brittebo, E. (2012) Proangiogenic effects of environmentally relevant levels of bisphenol A in human primary endothelial cells. Arch Toxicol. 86(3): 465-74

38. Privratsky JR1, Newman PJ. (2014) PECAM-1: regulator of endothelial junctional integrity. Cell Tissue Res.355(3): 607-19.

39. Gliemann, L., Rytter, N., Piil, P., Nilton, J., Lind, T., Nyberg, M., Cocks, M., Hellsten, Y. (2018) The Endothelial Mechanotransduction Protein Platelet Endothelial Cell Adhesion Molecule-1 Is Influenced by Aging and Exercise Training in Human Skeletal Muscle. Front Physiol. 9: 1807

40. Castaldi, A., Dodia, R.M., Orogo, A.M., Zambrano, C.M., Najor, R.H., Gustafsson, Å.B., Heller, Brown, J., Purcell, N.H. (2017) Decline in cellular function of aged mouse c-kit+ cardiac progenitor cells. $J$ Physiol. 595(19): 6249-6262.

41. Camussi, G.; Deregibus, M.C.; Bruno, S.; Grange, C.; Fonsato, V.; Tetta, C. (2011) Exosome/microvesiclemediated epigenetic reprogramming of cells. Am. J. Cancer Res. 1: 98-110.

42. Khayrullin, A., Krishnan, P., Martinez-Nater, L., Mendhe, B., Fulzele, S., Liu, Y., Mattison, J.A., Hamrick, M.W. (2019) Very Long-Chain C24:1 Ceramide Is Increased in Serum Extracellular Vesicles with Aging and Can Induce Senescence in Bone-Derived Mesenchymal Stem Cells. Cells. 8(1): 1-11

43. Carmona, A., Guerrero, F., Buendia, P., Obrero. T., Aljama, P., Carracedo, J. (2017) Microvesicles Derived from Indoxyl Sulfate Treated Endothelial Cells Induce Endothelial Progenitor Cells Dysfunction. Front Physiol. 8: 111

44. Ståhl, A.L., Johansson, K., Mossberg, M., Kahn, R., Karpman, D. (2019) Exosomes and microvesicles in normal physiology, pathophysiology, and renal diseases. Pediatr Nephrol. 34(1): 11-30.

45. Trinh, N.T., Yamashita, T., Tu, T.C., Kato, T., Ohneda, K., Sato, F., Ohneda, O. (2016) Microvesicles enhance the mobility of human diabetic adipose tissue-derived mesenchymal stem cells in vitro and improve wound healing in vivo. Biochem Biophys Res Commun. 473(4): 1111-1118.

46. Genís, L., Gonzalo, P., Tutor, A.S., Gálvez, B.G., Martínez-Ruiz, A., Zaragoza, C., Lamas, S., Tryggvason, K., Apte, S.S., Arroyo, A.G.(2007) Functional interplay between endothelial nitric oxide synthase and membrane type 1 matrix metalloproteinase in migrating endothelial cells. Blood. 110(8): 2916-23. 